\title{
Internet-Based Cognitive Behavioral Therapy With Real-Time Therapist Support via Videoconference for Patients With Obsessive-Compulsive Disorder, Panic Disorder, and Social Anxiety Disorder: Pilot Single-Arm Trial
}

Kazuki Matsumoto ${ }^{1,2}$, MPH; Chihiro Sutoh ${ }^{3}, \mathrm{MD}, \mathrm{PhD}$; Kenichi Asano ${ }^{2}, \mathrm{PhD}$; Yoichi Seki ${ }^{1,2}$, PhD; Yuko Urao ${ }^{1,2}$, $\mathrm{PhD}$; Mizue Yokoo ${ }^{2}, \mathrm{PhD}$; Rieko Takanashi ${ }^{2}$, PhD; Tokiko Yoshida ${ }^{2}, \mathrm{MPH}$; Mari Tanaka ${ }^{2}, \mathrm{PhD}$; Remi Noguchi ${ }^{2}$, $\mathrm{PhD}$; Shinobu Nagata ${ }^{2}, \mathrm{PhD}$; Keiko Oshiro ${ }^{2}$, PhD; Noriko Numata ${ }^{1,2}$, PhD; Motohisa Hirose ${ }^{2}$, PhD; Kensuke Yoshimura ${ }^{4}, \mathrm{MD}, \mathrm{MPH}$; Kazue Nagai ${ }^{5}, \mathrm{PhD}$; Yasunori Sato ${ }^{6}, \mathrm{PhD}$; Taishiro Kishimoto ${ }^{7}, \mathrm{MD}, \mathrm{PhD}$; Akiko Nakagawa ${ }^{1,2}$, $\mathrm{MD}, \mathrm{PhD}$; Eiji Shimizu ${ }^{2,3}, \mathrm{MD}, \mathrm{PhD}$

\footnotetext{
${ }^{1}$ United Graduate School of Child Development, Osaka University, Kanazawa University, Hamamatsu University School of Medicine, Chiba University and University of Fukui, Osaka, Japan

${ }^{2}$ Research Center for Child Mental Development, Graduate School of Medicine, Chiba University, Chiba, Japan

${ }^{3}$ Department of Cognitive Behavioral Physiology, Graduate School of Medicine, Chiba University, Chiba, Japan

${ }^{4}$ Research Center for Medical Economics Administration, Chiba University Hospital, Chiba, Japan

${ }^{5}$ Reseach and Education Center of Health Sciences, Gunma University Graduate School of Health Sciences, Gunma, Japan

${ }^{6}$ Department of Preventive Medicine and Public Health, Keio University, Tokyo, Japan

${ }^{7}$ Department of Neuropsychiatry, Keio University School of Medicine, Tokyo, Japan
}

\section{Corresponding Author:}

Chihiro Sutoh, MD, PhD

Department of Cognitive Behavioral Physiology

Graduate School of Medicine

Chiba University

1-8-1, Chuo-ku, Chiba-shi

Chiba,

Japan

Phone: 81432262027

Email: csutoh@graduate.chiba-u.jp

\section{Related Article:}

Comment in: https://www.jmir.org/2020/8/e13234

\section{Abstract}

Background: Cognitive behavioral therapy (CBT) is the first-line treatment for adults with obsessive-compulsive disorder (OCD), panic disorder (PD), and social anxiety disorder (SAD). Patients in rural areas can access CBT via the internet. The effectiveness of internet-delivered cognitive behavioral therapy (ICBT) has been consistently shown, but no clinical studies have demonstrated the feasibility of ICBT with real-time therapist support via videoconference for OCD, PD, and SAD at the same time.

Objectives: This study aimed to evaluate the feasibility of videoconference-delivered CBT for patients with OCD, PD, or SAD.

Methods: A total of 30 Japanese participants (mean age 35.4 years, SD 9.2) with OCD, SAD, or PD received 16 sessions of individualized videoconference-delivered CBT with real-time support of a therapist, using tablet personal computer (Apple iPad Mini 2). Treatment involved individualized CBT formulations specific to the presenting diagnosis; all sessions were provided by the same therapist. The primary outcomes were reduction in symptomatology, using the Yale-Brown obsessive-compulsive scale (Y-BOCS) for OCD, Panic Disorder Severity Scale (PDSS) for PD, and Liebowitz Social Anxiety Scale (LSAS) for SAD. The secondary outcomes included the EuroQol-5 Dimension (EQ-5D) for Quality of Life, the Patient Health Questionnaire (PHQ-9) for depression, the Generalized Anxiety Disorder (GAD-7) questionnaire for anxiety, and Working Alliance Inventory-Short Form (WAI-SF). All primary outcomes were assessed at baseline and at weeks 1 (baseline), 8 (midintervention), 
and 16 (postintervention) face-to-face during therapy. The occurrence of adverse events was observed after each session. For the primary analysis comparing between pre- and posttreatments, the participants' points and 95\% CIs were estimated by the paired $t$ tests with the change between pre- and posttreatment.

Results: A significant reduction in symptom of obsession-compulsion (Y-BOCS=-6.2; Cohen $d=0.74 ; 95 \%$ CI -9.4 to -3.0 , $P=.002)$, panic (PDSS $=-5.6$; Cohen $d=0.89 ; 95 \% \mathrm{CI}-9.83$ to $-1.37 ; P=.02)$, social anxiety $(\mathrm{LSAS}=-33.6$; Cohen $d=1.10 ; 95 \%$ $\mathrm{CI}-59.62$ to $-7.49, P=.02$ ) were observed. In addition, depression (PHQ-9=-1.72; Cohen $d=0.27 ; 95 \% \mathrm{CI}-3.26$ to $-0.19 ; P=.03$ ) and general anxiety (GAD-7=-3.03; Cohen $d=0.61 ; 95 \% \mathrm{CI}-4.57$ to $-1.49, P<.001)$ were significantly improved. Although there were no significant changes at 16 weeks from baseline in EQ-5D (0.0336; Cohen $d=-0.202 ; 95 \%$ CI -0.0198 to 0.00869 ; $P=.21$ ), there were high therapeutic alliance (ie, WAI-SF) scores (from 68.0 to 73.7 ) throughout treatment, which significantly increased $(4.14 ; 95 \%$ CI 1.24 to $7.04 ; P=.007)$. Of the participants, $86 \%(25 / 29)$ were satisfied with videoconference-delivered CBT, and $83 \%(24 / 29)$ preferred videoconference-delivered CBT to face-to-face CBT. An adverse event occurred to a patient with SAD; the incidence was $3 \%(1 / 30)$.

Conclusions: Videoconference-delivered CBT for patients with OCD, SAD, and SAD may be feasible and acceptable.

(J Med Internet Res 2018;20(12):e12091) doi: 10.2196/12091

\section{KEYWORDS}

clinical trial; cognitive behavioral therapy; feasibility study; obsessive-compulsive disorder; panic disorder; social anxiety disorder; videoconference

\section{Introduction}

\section{Background}

Obsessive-compulsive disorder (OCD), panic disorder (PD), and social anxiety disorder (SAD) are the most common mental disorders and incur a huge burden throughout the lifespan [1-4]. Cognitive behavioral therapy (CBT) has been found to be effective in treating all of the 3 disorders [5-16]. Although CBT is an effective treatment, it is difficult for all patients to receive CBT because of problems of access to treatment such as expensive specialized medical treatment, lack of therapists, and uneven urban distribution. Known as telemental health, a new therapeutic approach, born out of technological innovation after the internet revolution, has solved these problems. A patient can now receive treatment from remote distance via the internet, regardless of physical or psychological barriers such as time, distance, and stigma from remote distance by the internet $[17,18]$. For example, in internet-delivered CBT (ICBT), users can receive their programmed treatment at any time, 24 hours a day. In addition, the therapist's involvement with the patient can be reduced, optimizing treatment costs. Furthermore, a therapist guide can be employed via remote treatment, by using videoconference in real time, without compromising linguistic and nonverbal communication with the patient as much as possible.

ICBT has been shown to be effective for OCD, PD, and SAD from several randomized controlled trials [19-35]. A recent systematic review and meta-analyses using 20 studies comparing ICBTs and face-to-face CBTs showed that ICBT and face-to-face treatment produced equivalent overall effects [36]. Target diseases in this meta-analysis included SAD, PD, and depression. In the other meta-analyses, comparing the effectiveness of ICBT and face-to-face CBT with anxiety disorders including OCD (defined according to the Diagnostic and Statistical Manual of Mental Disorder III [37], III-R [38], IV [39], and IV-TR or the International Classification of Diseases 9 or 10 [40-42]), there were no clear differences between them [43]. ICBT can be roughly divided into the 3 categories depending on how the therapist participates in the program [44]: programs with no therapist assistance [45]; programs with assistance, where the therapists assistance is minimal [46]; and live conversations on the internet, where the therapist is fully involved using videoconference [47,48]. Although the effectiveness of ICBT has been suggested, there is little knowledge about ICBT including videoconference. In telemental health, which is an important theme when considering the optimization of social resources, the effectiveness of ICBT should be examined based on the therapist's degree of involvement. In this study, we examined the feasibility of ICBT with real-time videoconference, where the therapists were fully involved in treatment.

\section{Videoconference-Delivered Cognitive Behavioral Therapy}

In videoconference-delivered CBT, the therapist and patient use video and audio links to have a therapeutic conversation, as in face-to-face CBT, which includes nonverbal information such as expressions, body language, voice volume, and tone. Therefore, among the ICBT options, this allows the patient and the therapist to have the strongest therapeutic relevance. In a situation where real-time communication with the patient is important, it is considered to be a powerful approach; for example, when the therapist can enhance motivation through role playing by performing internal sensory exposure in front of a patient with serious panic PD.

Mental health services for remote populations via videoconferences have yielded high satisfaction [17,49-52]. A systematic review of videoconference-delivered CBT trials, using 20 controlled studies, uncontrolled studies, case series, and case studies for anxiety disorders including posttraumatic stress disorder (PTSD) using the criteria of the Diagnostic and Statistical Manual of Mental Disorders (DSM-IV-TR), suggested a medium to large effect size [53]. At the same time, there were no clinical studies about videoconference-delivered CBT for all of OCD, PD, and SAD. Comorbidity has often been seen between OCD, PD, and SAD [54]; clinical trials of CBT with 
additional remote systems to determine videoconference-delivered CBT adaptation to normal clinical scenes are thus meaningful. A randomized controlled trial compared OCD using professional videoconferencing equipment $(\mathrm{n}=10)$ with self-help $(\mathrm{n}=10)$ and wait-list $(\mathrm{n}=10)$ controls [51]. The results indicated large effect sizes (Cohen $d=2.1-2.5$ ); in addition, $60 \%(6 / 10)$ of participants in the videoconference condition achieved clinically significant changes at posttreatment and $50 \%(5 / 10)$ did so at a 3-month follow-up. Another controlled trial compared manualized CBT for PD and agoraphobia by videoconference $(n=11)$ with in-person CBT $(n=10)$ [52]. The results indicated no significant difference between the conditions, but $81 \%$ (9/11) of participants in the videoconferencing condition were panic-free at posttreatment and $91 \%(10 / 11)$ at a 9-month follow-up; this indicated a very large effect size for all panic and agoraphobia symptoms. An uncontrolled trial, using 24 participants with SAD, applied acceptance-based behavioral therapy via videoconference [50] and found that $54 \%(13 / 24)$ of participants did not meet DSM-IV-TR criteria for SAD at posttreatment. Large effect sizes for all social anxiety symptoms (Cohen $d=1.23-1.91$ ) were obtained at post-therapy and at a 3-month follow-up. In addition, it is known that videoconference-delivered therapy can develop a similarly strong therapeutic alliance with psychotherapy clients as in-person therapy $[49,55]$.

Nevertheless, during this trial, the only national university hospital with a CBT specialized outpatient in Japan was at our facility alone, the Chiba University; most patients do not have access to this treatment. For patients in Japan to receive CBT via the internet, it was necessary to examine the feasibility of videoconference-delivered CBT.

\section{Objective of This Study}

Previous studies have consistently demonstrated the effectiveness of videoconference-delivered CBT, but they have small samples sizes and were conducted in Western countries. Therefore, this pilot study utilized an open trial to examine the feasibility and preliminary effectiveness of in-home CBT via videoconference for Japanese adults with OCD [49], PD, and SAD. It was hypothesized that videoconference-delivered CBT would be effective to reduce the symptomatology for each disorder from pre- to posttreatment and acceptable to Japanese participants.

\section{Methods}

\section{Study Design}

This study was conducted as a single-arm, open trial at the academic outpatient clinic of the Cognitive Behavioral Therapy Center of Chiba University Hospital between March 2017 and March 2018. Since this trial was the first to employ an individual videoconference-delivered CBT intervention design against OCD, PD and SAD in Japan, a single-arm trial examining baseline predictors rather than effectiveness was considered to be an appropriate design [56].

\section{Ethics and Dissemination}

This trial was approved by the Institutional Review Board of Chiba University Hospital (reference number: G28038). The clinical trial registration number was UMIN000026609.

If an individual wished to participate in the trial, they had to contact the study trial office, where they were informed about the study objectives and asked to confirm whether they were willing to participate. Furthermore, they were assured absolute anonymity. They had to fill out an informed consent form for participation in this study. All participants were informed that they could continue receiving conventional drug treatments from their primary doctors. We practiced videoconferencing twice with participants.

\section{Participants and Eligibility Criteria}

The study participants were recruited through posters and leaflets placed at medical institutions in Chiba Prefecture, through the official Web-based advertisements at the Cognitive Behavioral Therapy Center of Chiba University Hospital and by referrals from their primary care doctors or psychiatrists. After email or telephone screening through Web-based app, the participants visited our center and were diagnosed with OCD, $\mathrm{SAD}$, or PD using the Mini-International Neuropsychiatric Interview [57,58].

Inclusion criteria for this study included informed consent to participate in the study; having a primary diagnosis of OCD, PD, or SAD; aged between 19 and 65 years, and having access to the internet at home. Comorbid mental disorders-including major depressive disorder, other anxiety disorders, and eating disorders-were permitted if they were clearly secondary, considering that this trial should reflect routine clinical practice. The exclusion criteria were organic brain damage, dementia, psychotic disorders, serious drug dependence, recurrent suicidal and antisocial behaviors, and severe somatic conditions. Participants, who used psychotropic drugs, including selective serotonin reuptake inhibitors and benzodiazepines, were asked to report all of changes regarding pharmacotherapy during the study period.

\section{Intervention}

The participants entered a Web conference room by clicking a URL in an email sent from their therapists. The intervention was conducted at a 50-min session once a week for 16 weeks. The modules were derived from previous studies on in-person CBT for OCD [59], PD [60], and SAD [61] in Japan and included psychoeducation, exposure exercises, behavioral experiments, and homework assignments.

\section{Therapists and Therapy Quality Control}

Videoconference-delivered CBT was delivered by 12 therapists, who were experienced in face-to-face CBT for patients with OCD, PD, and/or SAD (including 7 clinical psychologists, 2 psychiatric social workers, 1 nurse, 1 psychiatric pharmacist, and 1 psychiatrist). Therapists were trained in CBT programs for patients with OCD, PD, and SAD and attended weekly group-supervision sessions with other therapists as well as undergoing individual supervision by a senior supervisor. All therapists had completed a CBT training course (Chiba 
Improving Access to Psychological Therapies project: Chiba-IAPT) [62]. Of the therapists, 6 were female, with an average age of 43.5 years (SD 7.5) and an average of 2.2 years of clinical experience (SD 6.4) at the beginning of the study. Senior supervisors assessed the quality of the videoconference-delivered CBT sessions using the Cognitive Therapy Scale-Revised [63,64], a revision of the Cognitive Therapy Scale designed by Young and Beck (unpublished data $[65,66])$.

\section{Visual Aids}

The use of visual aids facilitates the learning process by enhancing motivation and understanding of complex matters [67]. Therefore, visual aids were used in each program to enhance the participants' understanding. The visual aids consisted of several slides including key concepts of CBT. The therapists conducted CBT sessions with the visual aids by using the screen-sharing function of the videoconference software, sending them to the participants as password-protected homework slides by email after each session.

\section{Hardware}

The therapists used 2 Surface Pro 2 computers-2-in-1 detachable produced by Microsoft, running Windows 10 Pro (Microsoft Corporation, US). The display size was 10.6 inches and a resolution of $1920 \times 1080$ pixels. Each participant was lent an iPad Mini 2 (Apple Inc, US) with a 7.9-inch display and a 2048×1536-pixel resolution.

\section{Software for Videoconference}

A total of 3 licenses for videoconference software (Cisco WebEx, Milpitas, CA, USA) were used in this trial. This system has been awarded ISO27001 certification (regarding handling of information security) and SSAE16 (Statement of Standards for Attestation Engagements No. 16: former SAS 70) compliance certification (issued by a third party). It also complies with the United States Health Insurance Portability and Accountability Act. WebEx's use of a switching network along with a 128-bit Secure Sockets Layer encryption and public key infrastructure is regarded by the Japan Ministry of Health, Labor and Welfare to have solved the problem of safety, as reported in their "Guidelines on Safety Management of Medical Information System Version 4.3" in March 2016 [68]. Since the stability and safety of the software are excellent and it sufficiently protects personal information, we judged WebEx to be sufficiently reliable for this study.

\section{Measures of Primary Outcomes}

The most commonly used scales to measure symptoms of each disorder were used as follows: the Yale-Brown Obsessive-Compulsive Scale (Y-BOCS) for OCD symptoms [69,70], the Panic Disorder Severity Scale (PDSS) for PD symptoms [71,72], and the Liebowitz Social Anxiety Scale (LSAS) for SAD symptoms [73,74].

To calculate responsiveness to treatment and the remission rate after the intervention, the criteria of the previous studies regarding the severity rating scale of each disorder was used $[62,64,65]$. For OCD, treatment response was defined as a $35 \%$ or greater reduction in the total Y-BOCS score, and remission was defined as a final Y-BOCS score of $\leq 14$ [75]. For PD, treatment response was defined as a $40 \%$ or greater reduction in total PDSS score, and remission was defined as a final PDSS score of $\leq 5$ [76]. For SAD, treatment response was defined as a $31 \%$ or greater reduction in total LSAS score, and remission was defined as a final LSAS score of $\leq 36$ [73].

\section{Measures of Secondary Outcomes}

We used the EuroQol-5 Dimension (EQ-5D) to measure health-related quality of life $[77,78]$. This trial measured the psychological bond between therapist and participant using the Working Alliance Inventory-Short Form (WAI-SF) [79], depressive symptoms using the Patient Health Questionnaire-9 (PHQ-9) [80,81], and generalized anxiety symptoms using the Generalized Anxiety Disorder-7 (GAD-7) [82,83]. The definition of the response in PHQ-9 and GAD-7 was defined as a $50 \%$ reduction in total score. We used 7-point Likert scale format to measure participants' satisfaction about videoconference-delivered CBT as follows: "Very dissatisfied," "Dissatisfied," "Slightly dissatisfied," "Neutral," "Slightly satisfied," "Satisfied," and "Very satisfied." In addition, the participants were asked about preference of videoconference-delivered CBT or face-to-face CBT as follows: "If you could choose in the future, would you wish to receive treatment with either face-to-face or videoconference CBT?" Participants answered using a 7-point Likert scale as follows: "Clearly prefer face-to-face," "Prefer face-to-face," "Slightly prefer face-to-face," "Neutral," "Slightly prefer videoconference-delivered CBT," "Prefer videoconference-delivered CBT," and "Clearly prefer videoconference-delivered CBT."

\section{Data Setting and Locations}

Participant and therapists used the Numbers app for iOS to run the digital questionnaires, and the therapist asked each participant to answer them by themselves on the tablet PC at weeks 1, 8, and 16. Each participant sent an email with the completed questionnaires of all primary outcomes (Y-BOCS, PDSS, and LSAS) and part of secondary outcomes (EQ-5D, PHQ-9, and GAD-7) to their therapist before each session and sent an email with the completed questionnaires of the secondary outcomes (WAI-SF and satisfaction/preference) attached after session. The therapist checked outcomes and evaluated the symptoms during the session, collaborating with the participant. The collected data were registered to the server of DATATRAK ONE (DATATRAK International Inc, US) as Web case registration system by the lead author and managed by the data management office of Chiba University. This study adhered to the CONSORT-EHEALTH guidelines for improving and standardizing the report of Web-based and mobile health interventions [84].

\section{Adverse Events}

To confirm the occurrence of adverse events after intervention, the therapist asked the patient about their physical and mental condition at the end of each session and instructed all participants to report all adverse events by email. 


\section{Statistical Analysis}

Statistical analysis and reporting of this trial were conducted in accordance with the CONSORT-EHEALTH guidelines [84]. All statistical analyses were described in the statistical analysis plan, which was fixed before the database lock. All efficacy analyses were primarily based on the full analysis set, which included all patients who had received at least one session of the videoconference-delivered CBT treatment. For baseline variables, summary statistics were constructed, employing frequencies and proportions for categorical data and means and SDs for continuous variables. Baseline variables were compared using the Fisher exact test for categorical outcomes and the unpaired $t$ test for continuous variables. For the primary analysis comparing between pre- and posttreatments, the points and their 95\% CIs were estimated by the paired $t$ tests with the change at week 16 from baseline in EQ-5D index scores for all of the patients in Y-BOCS for OCD, PDSS for PD, and in LSAS for $\mathrm{SAD}$. For comparison among the 3 disorders, a one-way analysis of variance was used. Analyses of secondary outcomes were performed in the same manner as the primary analysis.

In addition, we calculated Cohen $d$ pre-post effect sizes by calculating the mean differences between pre- and posttreatments, dividing by the pooled SDs. We also adopted the criteria that a Cohen $d$ of $>0.20$ was a small effect, that of $>0.50$ was a medium effect, and that of $>0.80$ was a large effect [85]. All $P$ values were two-sided; a value of $P<.05$ was considered statistically significant. Statistical analyses were performed using SAS software version 9.4 (SAS Institute, Cary, North Carolina, USA) and the R statistical program version 2.13 (The R Foundation, Vienna, Austria).

\section{Results}

\section{Recruitment}

Figure 1 shows the participant flow. A total of 37 patients applied to participate through our website. After email or telephone screening, 6 patients were excluded; 1 did not meet one of the inclusion criteria due to epilepsy and 5 declined to participate because of long distance to our hospital. After the screening, 31 attended the face-to-face baseline assessment, and one did not meet one of the inclusion criteria due to high risk of suicide. Finally, 30 patients were enrolled to the study.

\section{Attrition}

Of the participants eligible to take part in the study, $1 \mathrm{SAD}$ participant with major depressive disorder dropped out after 9 sessions because of worsening of his depressive state. The remaining 97\% (29/30) completed the full course of videoconference-delivered CBT. All data at point each assessment (screening, session 1, session 8, and session 16) were statistically analyzed.

\section{Clinical and Demographic Characteristics}

The sample included 30 participants (6 males and 24 females), aged 20 to 54 years (mean 35.4 years, SD 9.2), education 10 to 19 years (mean 14.8 years, SD 2.1). Apart from primary diagnoses, a summary of the participants' demographic and diagnostic information is presented in Table 1. Moreover, 15 participants continued to receive pharmacotherapy during the trial (4 fluvoxamine, 2 escitalopram, 1 sertraline, 1 paroxetine hydrochloride, 1 duloxetine, 1 mirtazapine, 1 trazodone, 1 ethyl loflazepate, 1 alprazolam, and 1 clotiazepam).

\section{Primary Outcomes}

There were significant reductions for each symptoms of obsession-compulsion (Y-BOCS $=-6.2$; Cohen $d=0.74 ; 95 \% \mathrm{CI}$ -9.4 to $-3.0 ; P=.002)$, panic (PDSS=-5.6; Cohen $d=0.89 ; 95 \%$ CI -9.83 to $-1.37 ; P=.02$ ), and social anxiety (LSAS=-33.3; Cohen $d=1.10 ; 95 \%$ CI -59.62 to $-7.49 ; P=.02)$. Of the participants with OCD, $20 \%(2 / 10)$ showed a treatment response, whereas $40 \%$ (4/10) went into remission [75]. Of the participants with $\mathrm{PD}, 60 \%(6 / 10)$ showed a treatment response and $50 \%$ $(5 / 10)$ went into remission [76]. Of the participants with SAD, $44 \%$ (4/9) showed a treatment response and 22\% (2/9) went into remission [73].

\section{Secondary Outcomes}

Figure 2 shows the change in the primary outcomes. Table 2 shows the mean change in the EQ-5D scores, at 16 sessions from baseline. The adjusted mean changes of the EQ-5D for all of the 3 disorders was $0.0336(95 \% \mathrm{Cl}-0.0198$ to 0.0869 ; $P=.21$ ), which showed that it was not significant and showed a small effect size (Cohen $d=-0.202$ ).

Figure 3 also shows the change in the secondary outcomes. The mean changes in the PHQ-9 and GAD-7 scores reflected significant decreases in total participants for the 3 disorders (Table 3). The mean change in the WAI-SF reflected a significant increase for the total sample. Table 4 shows participants' satisfaction with and preferences for videoconference-delivered CBT. As the ratings "very satisfied" and "satisfied" were combined, the majority of participants (86\%, 25/29) reported being satisfied with videoconference-delivered CBT. In that case, the ratings "slightly prefer videoconference-delivered CBT," "prefer videoconference-delivered CBT," and "clearly prefer videoconference-delivered CBT" were combined; 83\% (24/29) of the participants preferred videoconference-delivered CBT to face-to-face CBT. Conversely, 7\% (2/29) of them preferred face-to-face CBT to videoconference-delivered CBT. 
Figure 1. Participant flow.

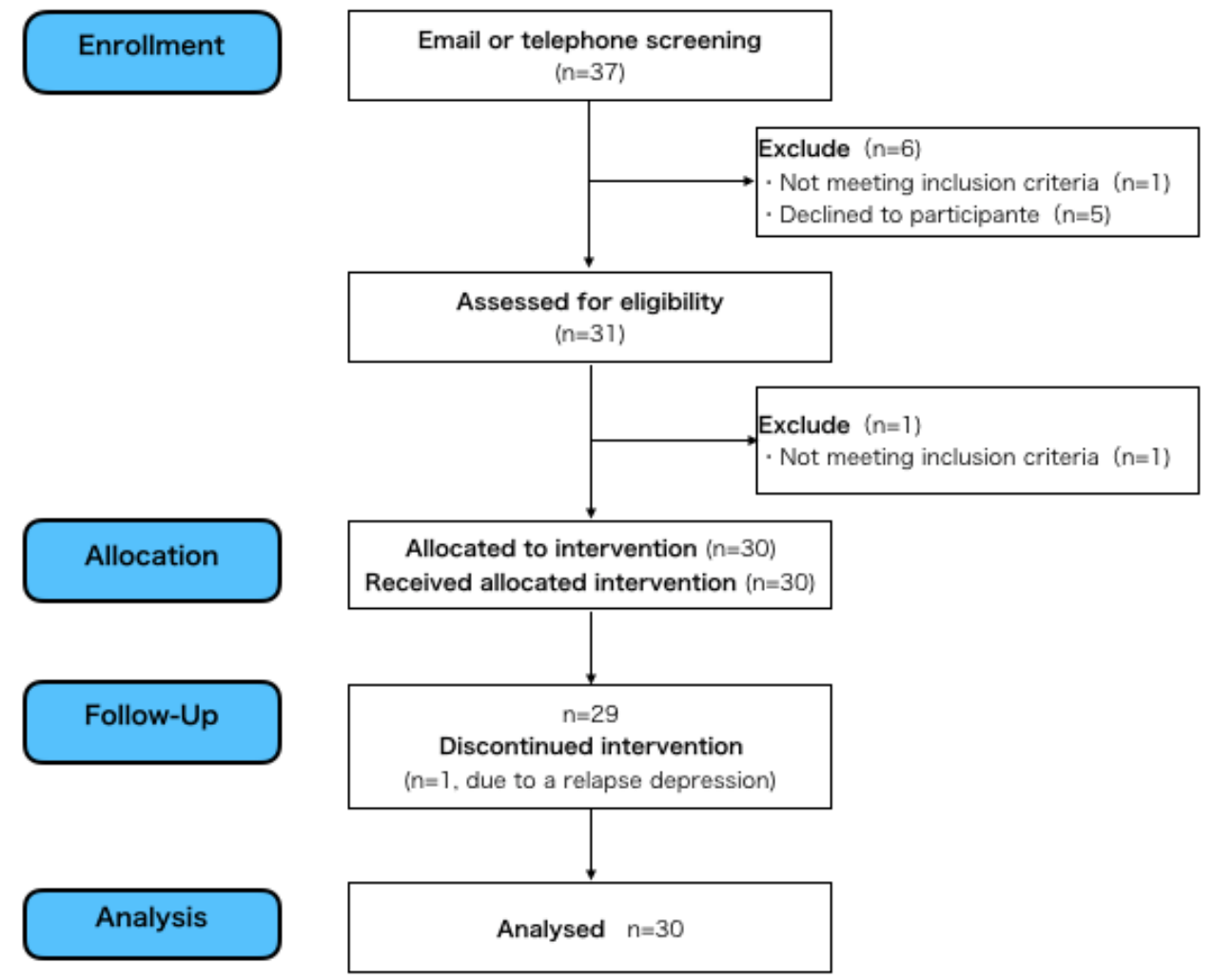

Table 1. Clinical and demographic characteristics of participants $(\mathrm{N}=30)$.

\begin{tabular}{|c|c|c|c|c|}
\hline Characteristics & All & $\mathrm{OCD}^{\mathrm{a}}$ & $\mathrm{PD}^{\mathrm{b}}$ & $\mathrm{SAD}^{\mathrm{c}}$ \\
\hline Age (years), mean (SD) & $35.4(9.2)$ & $37.7(6.9)$ & $38.8(9.8)$ & $29.7(8.6)$ \\
\hline \multicolumn{5}{|l|}{$\operatorname{Sex}, \mathbf{n}(\%)$} \\
\hline Male & $6(20)$ & $2(6)$ & $0(0)$ & $4(13)$ \\
\hline Female & $24(80)$ & $8(27)$ & $10(33)$ & $6(20)$ \\
\hline Employment, n (\%) & $11(36)$ & $5(17)$ & $2(6)$ & $4(13)$ \\
\hline Combined pharmacotherapy, n (\%) & $15(50)$ & $6(20)$ & $5(17)$ & $4(13)$ \\
\hline Videophone use experience, $\mathrm{n}(\%)$ & $15(50)$ & $4(13)$ & $6(20)$ & $5(17)$ \\
\hline \multicolumn{5}{|l|}{ Comorbid disorders, n (\%) } \\
\hline Depression & $5(17)$ & $1(3)$ & $1(3)$ & $3(10)$ \\
\hline Panic/agoraphobia & $2(6)$ & $2(6)$ & $\mathrm{N} / \mathrm{A}^{\mathrm{d}}$ & N/A \\
\hline $\mathrm{PTSD}^{\mathrm{e}}$ & $1(3)$ & N/A & $1(3)$ & N/A \\
\hline Alcohol dependence & $1(3)$ & N/A & N/A & $1(3)$ \\
\hline Bulimia nervosa & $1(3)$ & N/A & N/A & $1(3)$ \\
\hline $\mathrm{GAD}^{\mathrm{f}}$ & $3(10)$ & $2(6)$ & N/A & $1(3)$ \\
\hline
\end{tabular}

${ }^{\mathrm{a} O C D}$ : obsessive-compulsive disorder.

${ }^{\mathrm{b}} \mathrm{PD}$ : panic disorder.

${ }^{\mathrm{c}} \mathrm{SAD}$ : social anxiety disorder.

${ }^{\mathrm{d}} \mathrm{N} / \mathrm{A}$ : not applicable.

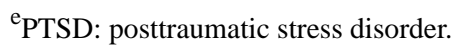

${ }^{f} \mathrm{GAD}$ : generalized anxiety disorder. 
Figure 2. Change of primary outcomes. LSAS: Liebowitz Social Anxiety Scale; PDSS: Panic Disorder Severity Scale; Y-BCOS: Yale-Brown Obsessive-Compulsive Scale.

\section{A: Y-BOCS}

35

30

25

20

15

10

5

0

Screening Session $1 \quad$ Session 8 Session 16

\section{B: PDSS}

25

20

15

10

5

0

Screening Session 1 Session 8 Session 16

\section{C: LSAS}

\section{0}

120

100

80

60

40

20

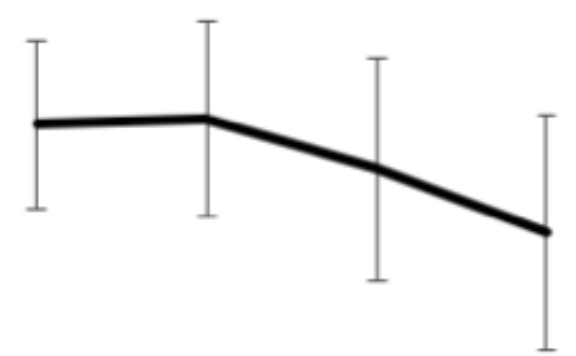

0

Screening Session 1 Session 8 Session 16

Table 2. Mean change in EuroQol-5 Dimension score.

\begin{tabular}{llll}
\hline Disorder & Mean change $(95 \% \mathrm{CI})$ & $P$ value (paired $t$ test $)$ & $P$ value $(F$ test $)$ \\
\hline All $(\mathrm{n}=29)$ & $0.0336(-0.0198$ to 0.0869$)$ & .21 & N/A $^{\mathrm{a}}$ \\
$\operatorname{OCD}^{\mathrm{b}}(\mathrm{n}=10)$ & $0.0488(-0.0577$ to 0.1553$)$ & .33 & .91 \\
$\operatorname{PD}^{\mathrm{c}}(\mathrm{n}=10)$ & $0.0305(-0.0393$ to 0.1003$)$ & .35 & .91 \\
$\operatorname{SAD}^{\mathrm{d}}(\mathrm{n}=9)$ & $0.0201(-0.1188$ to 0.1591$)$ & .75 & .91 \\
\hline
\end{tabular}

${ }^{\mathrm{a} N} / \mathrm{A}$ : not applicable.

${ }^{\mathrm{b}} \mathrm{OCD}$ : obsessive-compulsive disorder.

${ }^{\mathrm{c}} \mathrm{PD}$ : panic disorder.

${ }^{\mathrm{d}}$ SAD: social anxiety disorder. 
Figure 3. Change of secondary outcomes. EQ-5D-5L: EuroQol-5 Dimension; GAD-7: Generalized Anxiety Disorder-7; PHQ-9: Patient Health Questionnaire-9; WAI-SF: Working Alliance Inventory-Short Form.

\section{D: EQ-5D}

1.00

0.95

0.90

0.85

0.80

0.75

0.70

0.65

0.60

0.55

0.50

$\begin{array}{llll}\text { Screening } & \text { Session } 1 & \text { Session } 8 & \text { Session } 16\end{array}$
E: PHQ-9

18

16

14

12

10

8

6

4

0

$\begin{array}{llll}\text { Screening } & \text { Session } 1 & \text { Session } 8 & \text { Session } 16\end{array}$

\section{F: GAD-7}

16

14

12

10

8

6

4

2

0

$\begin{array}{llll}\text { Screening } & \text { Session } 1 & \text { Session } 8 & \text { Session } 16\end{array}$

\section{G: WAI-SF}

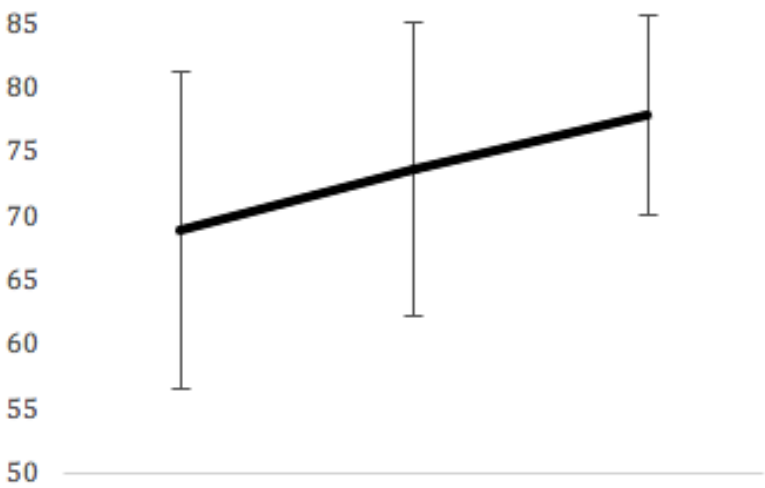

Session $1 \quad$ Session 8 
Table 3. Mean changes in secondary outcomes.

\begin{tabular}{|c|c|c|c|}
\hline Measures and Disorder & Mean change, $t$ value $(95 \% \mathrm{CI})$ & $P$ value (paired $t$ test) & $P$ value $(F$ test $)$ \\
\hline \multicolumn{4}{|l|}{ PHQ-9 ${ }^{\mathbf{a}}$} \\
\hline All $(n=29)$ & $-1.72(-3.26$ to -0.19$)$ & .03 & $\mathrm{~N} / \mathrm{A}^{\mathrm{b}}$ \\
\hline $\mathrm{OCD}^{\mathrm{c}}(\mathrm{n}=10)$ & $-1.70(-4.52$ to 1.12$)$ & .21 & .27 \\
\hline $\mathrm{PD}^{\mathrm{d}}(\mathrm{n}=10)$ & $-0.30(-1.65$ to 1.05$)$ & .63 & .27 \\
\hline $\operatorname{SAD}^{\mathrm{e}}(\mathrm{n}=9)$ & $-3.33(-7.56$ to 0.89$)$ & .11 & .27 \\
\hline \multicolumn{4}{|l|}{ GAD- $7^{\mathbf{f}}$} \\
\hline All $(n=29)$ & $-3.03(-4.57$ to -1.49$)$ & $<.001$ & N/A \\
\hline OCD $(n=10)$ & $-.50(-6.37$ to -0.63$)$ & .002 & .68 \\
\hline $\mathrm{PD}(\mathrm{n}=10)$ & $-2.10(-3.43$ to 0.77$)$ & .006 & .68 \\
\hline $\operatorname{SAD}(n=9)$ & $-3.56(-8.02$ to 0.91$)$ & .10 & .68 \\
\hline \multicolumn{4}{|l|}{ WAI-SF ${ }^{\mathrm{g}}$} \\
\hline All $(n=29)$ & $4.14(1.24$ to 7.04$)$ & .007 & N/A \\
\hline OCD $(n=10)$ & $3.00(-1.77$ to 7.77$)$ & .19 & .85 \\
\hline $\mathrm{PD}(\mathrm{n}=10)$ & $4.80(-0.42$ to 10.02$)$ & .07 & .85 \\
\hline SAD $(n=9)$ & $4.67(-2.66$ to 11.99$)$ & .18 & .85 \\
\hline
\end{tabular}

${ }^{\text {a}}$ PHQ-9: Patient Health Questionnaire-9.

${ }^{\mathrm{b}} \mathrm{N} / \mathrm{A}$ : not applicable.

${ }^{\mathrm{c} O C D}$ : obsessive-compulsive disorder.

${ }^{\mathrm{d}} \mathrm{PD}$ : panic disorder.

${ }^{\mathrm{e}} \mathrm{SAD}$ : social anxiety disorder.

${ }^{f}$ GAD-7: Generalized Anxiety Disorder-7.

gWAI-SF: Working Alliance Inventory-Short Form. 
Table 4. Satisfaction and preference.

\begin{tabular}{ll}
\hline Answer options & $\mathrm{n}(\%)$ \\
\hline Satisfaction & $0(0)$ \\
$\quad$ Very dissatisfied & $0(0)$ \\
Dissatisfied & $1(3)$ \\
Slightly dissatisfied & $0(0)$ \\
Neutral & $3(10)$ \\
Slightly satisfied & $9(31)$ \\
Satisfied & $16(55)$ \\
Very satisfied & \\
Preference & $0(0)$ \\
Clearly prefer face-to-face & $1(3)$ \\
Prefer face-to-face & $1(3)$ \\
Slightly prefer face-to-face & $3(10)$ \\
Neutral & $10(34)$ \\
Slightly prefer videoconference-delivered CBT & $6(21)$ \\
Prefer videoconference-delivered CBT & $8(28)$ \\
Clearly prefer videoconference-delivered CBT & \\
\hline
\end{tabular}

${ }^{\mathrm{a} C B T}$ : cognitive behavioral therapy.

\section{Adverse Events}

A total of 3 patients reported adverse events, including depression relapse, headache, and feeling of exhaustion. The depressive symptoms of $1 \mathrm{SAD}$ patient with depressive disorder worsened between the ninth and tenth sessions, when he was travelling with his friend. We identified this as a serious adverse event at the tenth session. He wanted to decline continuing with videoconference-delivered CBT and dropped out of the trial at that time. At 6 months after he received pharmacotherapy from his psychiatrist, he recovered the depressive episode. In addition, 1 PD participant reported a headache at the fourth session but recovered in the same day. Furthermore, 1 OCD patient reported a feeling of exhaustion after the 4 th session but recovered in the same day.

\section{Discussion}

\section{Principal Findings}

This study examined the feasibility of videoconference-delivered CBT in adult patients with mild to severe OCD, PD, and SAD. Interventions based on CBT were conducted for each group divided by primary diagnosis, and examination of symptom improvement and acceptance of patients was conducted before and after the intervention. We use different criteria for each disease looking at the rate of responders to treatment (defined as a 35\% reduction in Y-BOCS obsessive-compulsive symptoms, a $40 \%$ reduction in PDSS panic symptoms, and a $31 \%$ reduction in LSAS social anxiety symptoms); patients' satisfaction were also confirmed by using therapeutic alliance and patients' treatment acceptance. Improvement of the symptoms was confirmed in 3 disorders; it was found that the therapeutic alliance was achieved at a high level, and patients' satisfaction was extremely high. Therefore, this study showed the feasibility of ICBT with real-time support of therapists to Japanese patients except for depression [86].

\section{Feasibility of Videoconference-Delivered Cognitive Behavioral Therapy}

Regarding the other primary outcomes, the calculated Cohen $d$ for pre- to posttreatment were 0.74 for the Y-BOCS, 0.89 for the PDSS, and 1.10 for the LSAS. The Cohen $d$ scores were classified as medium and large. Though it is difficult to compare these studies because the characteristics of the patients and/or the methods were different, these results seem similar to those of our face-to-face CBT studies [59-61]. These medium and large effect sizes were also found in the previous studies of videoconference-delivered CBT (Cohen $d=1.4-2.5$ ) [50-52]. A previous videoconference-delivered CBT study for OCD reported that the treatment response rate was $60 \%(6 / 10)$. According to a systematic review about face-to-face CBT studies conducted between 2000 and 2014, the response rates were $43.3 \%$ for OCD, $53.2 \%$ for PD, and $45.3 \%$ for SAD [87]. The response rates in this study were $20 \%(2 / 10)$ for OCD, $60 \%$ $(6 / 10)$ for PD, and $44 \%$ (4/9) for SAD. Previous videoconference-delivered $\mathrm{CBT}$ studies reported that the remission rate for PD was $81 \%(9 / 11)$ [52] and that for SAD was 54\% (13/24) [50]. The remission rates in our studies were $40 \%$ (4/10) for OCD, 50\% (5/10) for PD, and 22\% (2/9) for $\mathrm{SAD}$. Although comparisons of these results must be done with caution, the response and remission rates of this study were comparable with those in the previous studies of in-person CBT and videoconference-delivered CBT. In the future, it will be necessary to verify the effectiveness of our videoconference-delivered CBT through a randomized controlled trial or noninferiority trial in comparison with 
face-to-face CBT or videoconference-delivered CBT with different methodology.

There was no significant change $(P=.21)$ in the EQ-5D scores for all of the 3 disorders, the calculated Cohen $d$ from pre- to posttreatment was -0.202 and classified as small. In addition, there were no significant differences in changes of the EQ-5D score among the 3 disorder groups $(P=.91)$. As described by the previous reports [88], our findings suggested that the EQ-5D was responsive in videoconference-delivered CBT for OCD, $\mathrm{PD}$, and SAD.

For the PHQ-9, a significant reduction between pre- and posttreatment was observed for the entire sample $(P=.03)$ There were no significant differences in the PHQ-9 changes among the 3 disorders $(P=.27)$. The effect size for the 3 disorders was small (Cohen $d=0.27$ ). After dividing each disorder, the effect sizes ranged from small to medium (OCD: Cohen $d=0.23$; PD: Cohen $d=0.07$; SAD: Cohen $d=0.64$ ). As for the GAD-7, a significant reduction pre- and posttreatment was observed for the entire sample $(P<.001)$. Although the change reflected a medium effect size for the entire sample (Cohen $d=0.61$ ), all were medium for each disorder (OCD: Cohen $d=0.75$; PD: Cohen $d=0.79$; SAD: Cohen $d=0.67)$. There were significant differences in changes between the OCD and PD groups (OCD: $P=.002$; PD: $P=.006$; SAD: $P=.10$ ) at week 16 . A previous study reported a response rate in GAD-7 of $50.9 \%$ following a computerized CBT program, for 1062 adults who had GAD-7 scores of 10 or more at baseline [89] including 75 patients with GAD, 47 with PD, 40 with SAD, and 18 with PTSD. In this study, the treatment response rate for the GAD-7 was $45 \%$ (13/29). The response rates of PHQ-9 and GAD-7 in this study were similar to those in a prior study [89]. Taken together, our results suggest that videoconference-delivered CBT for OCD, $\mathrm{PD}$, and SAD might secondarily ameliorate symptoms for generalized anxiety and depression.

More than half of the participants $(55 \%, 16 / 29)$ who completed the videoconference-delivered CBT reported the highest level of satisfaction ("very satisfied") with treatment via videoconferencing, whereas $31 \%(9 / 29)$ reported that they were "satisfied" (the second highest level). In other words, $86 \%$ $(25 / 29)$ of participants reported being satisfied with videoconference-delivered CBT. These results are consistent with those of previous studies [50,90]. Furthermore, 83\% (24/29) of the participants preferred videoconference-delivered CBT to face-to-face CBT. Conversely, 7\% (2/29) preferred face to face CBT to videoconference-delivered CBT. Taken together, these results indicated that videoconference-delivered CBT was generally accepted by Japanese participants with OCD and anxiety disorders.

The therapeutic alliance indicated by the total scores of WAI-SF significantly improved throughout the treatment, from 68.9 (SD $12.3)$ at week 1 to $77.9(\mathrm{SD} 7.7)$ at week $16(P=.007)$. The mean scores of the WAI-SF items were 5.7 (SD 0.97) at pretreatment, 6.1 (SD 0.95) at midtreatment, and 6.5 (SD 0.63) at posttreatment. These results were comparable with those of a previous study on videoconference-delivered CBT, where the WAI-SF scores increased from 5.22 (SD 0.42) to 5.60 (SD 0.90) in patients with SAD [50] and were 5.80 (SD 0.90) in patients with OCD [51]. Furthermore, these therapeutic alliance scores were comparable with those in a previous study on in-person CBT, where the WAI-SF scores increased from 5.78 (SD 0.94) to 5.93 (SD 0.90) in patients with PD and from 5.32 (SD 0.87) to 5.57 (SD 0.85) in patients with SAD [90]. Considering that lower alliance is known to be associated with dropout [90], the high alliance scores in this study can explain low dropout rate $(3 \%, 1 / 30)$.

The dropout rate of this study was 3\% (1/30), as 97\% (29/30) completed the videoconference-delivered CBT treatment. Dividing the 3 disorders, the dropout rate of $10 \%(1 / 10)$ of participants with SAD was comparable with that of a previous study of videoconference-delivered CBT $(17 \%, 4 / 24)$ [50] as well as a previous meta-analysis of 587 studies of in-person CBT between 1990 and 2010 (18\%) [91]. The dropout rate of $0 \%$ for OCD was comparable with that of a previous study of videoconference-delivered CBT $(0 \%, 0 / 10)$ [51] as well as the results of a meta-analysis of studies on in-person CBT published between 1993 and 2014 (15\%) [92]. The dropout rate of $0 \%$ for PD was similarly comparable with a previous study on videoconference-delivered CBT $(0 \%, 0 / 11)$ [52] as well as a meta-analysis of in-person CBT studies published between 1993 and $2002(12.7 \%)$ [93].

\section{Limitations}

This study has some limitations, including its small sample size, lack of a control group, unstandardized outcomes (satisfaction/preference of videoconference-delivered CBT), and long-term follow-up. Without a placebo control group and pharmacotherapy group, it remains unknown whether the observed improvements in symptom severity were merely the natural course, a result of the drug, or the effect of the intervention. Future studies should employ psychological placebo conditions and pharmacotherapy conditions. Thus, a 3-armed randomized controlled trial comparing pill placebo as the control group, videoconference-delivered CBT patients on antidepressants, and videoconference-delivered CBT patients who are drug-free should be designed and performed. We have been conducting a randomized controlled trial that includes the pharmacotherapy condition to provide greater insight into this CBT for PD since December 2016. In addition, we intend to conduct similar trials for OCD and SAD in the near future.

\section{Conclusions}

This study demonstrated the feasibility of CBT with real-time support by the therapist to remotely treat adult patients with symptoms of obsessive-compulsion or anxiety, examining the reduction in symptoms before and after the intervention, and patient acceptance. As it was found that the mutual relationship between therapists and patients can be built on a high level by patients and that patients felt satisfaction about remote treatment with real-time therapist support via videoconference, we believe that videoconference-delivered CBT can be easily implemented on a larger scale in present Japan where the internet is easily accessible. Future research should aim at increasing the reach of intervention and determining whether the intervention is indeed more approachable to people who are young patients or those with a low socioeconomic status. Related to this matter, because a patient's understanding level and information 
communication skills probably influence the effectiveness of remote treatment, future studies should be made on designs that consider the contents of support of the therapist beyond the absence or presence of guides.

\section{Acknowledgments}

The authors would like to thank Ms Ota and Ms Suwabe, nurses at the Cognitive Behavior Therapy Center, Chiba University Medical School Hospital for the smooth coordination between the therapists and the patients. They also thank Professor Hanaoka, Mr Oki, Ms Yamasaki, and other staff of the Clinical Research Center, Chiba University Medical School Hospital for ensuring the rigor of the study plan. Accurate data management was carried out thanks to Ms Shin and Professor Hanawa in the Data Management Center, Chiba University Medical School Hospital. The authors express their heartfelt appreciation to everyone for their cooperation.

This study was funded by the Japan Agency for Medical Research and Development (AMED; "Medical Digital Revolution Realization Project"; Second Public Inquiry, "Study on Database Infrastructure Construction for Medical Images and Others," aimed at utilization of Information Communication Technology and Artificial Intelligence, Clinical Research Evidence of Distant Psychiatric Medicine to establish guideline through the accumulation of databases and database construction for data utilization; grant 16929962). The AMED played no role in the collection, management, analysis, or interpretation of data and will not have any impact on the trial and the publication of the results.

\section{Conflicts of Interest}

None declared.

\section{References}

1. Kawakami N, Takeshima T, Ono Y, Uda H, Hata Y, Nakane Y, et al. Twelve-month prevalence, severity, and treatment of common mental disorders in communities in Japan: preliminary finding from the World Mental Health Japan Survey 2002-2003. Psychiatry Clin Neurosci 2005 Aug;59(4):441-452. [doi: 10.1111/j.1440-1819.2005.01397.x] [Medline: $\underline{16048450]}$

2. Kessler RC, Berglund P, Demler O, Jin R, Merikangas KR, Walters EE. Lifetime prevalence and age-of-onset distributions of DSM-IV disorders in the National Comorbidity Survey Replication. Arch Gen Psychiatry 2005 Jun;62(6):593-602. [doi: 10.1001/archpsyc.62.6.593] [Medline: 15939837]

3. Kessler RC, Angermeyer M, Anthony JC, Demyttenaere K, Gasquet I, Gluzman S, et al. Lifetime prevalence and age-of-onset distributions of mental disorders in the World Health Organization's World Mental Health Survey Initiative. World Psychiatry 2007 Oct;6(3):168-176 [ [FREE Full text] [Medline: 18188442]

4. Kessler RC, Petukhova M, Sampson NA, Zaslavsky AM, Wittchen H. Twelve-month and lifetime prevalence and lifetime morbid risk of anxiety and mood disorders in the United States. Int J Methods Psychiatr Res 2012 Sep;21(3):169-184 [FREE Full text] [doi: 10.1002/mpr.1359] [Medline: 22865617]

5. Marks IM, Swinson RP, Başoğlu M, Kuch K, Noshirvani H, O'Sullivan G, et al. Alprazolam and exposure alone and combined in panic disorder with agoraphobia. A controlled study in London and Toronto. Br J Psychiatry 1993 Jun;162:776-787. [Medline: $\underline{8101126]}$

6. Clark DM, Salkovskis PM, Hackmann A, Middleton H, Anastasiades P, Gelder M. A comparison of cognitive therapy, applied relaxation and imipramine in the treatment of panic disorder. Br J Psychiatry 1994 Jun;164(6):759-769. [Medline: 7952982]

7. Clark DM, Ehlers A, McManus F, Hackmann A, Fennell M, Campbell H, et al. Cognitive therapy versus fluoxetine in generalized social phobia: a randomized placebo-controlled trial. J Consult Clin Psychol 2003 Dec;71(6):1058-1067. [doi: 10.1037/0022-006X.71.6.1058] [Medline: 14622081]

8. Foa EB, Liebowitz MR, Kozak MJ, Davies S, Campeas R, Franklin ME, et al. Randomized, placebo-controlled trial of exposure and ritual prevention, clomipramine, and their combination in the treatment of obsessive-compulsive disorder. Am J Psychiatry 2005 Jan;162(1):151-161. [doi: 10.1176/appi.ajp.162.1.151] [Medline: 15625214]

9. Mitte K. A meta-analysis of the efficacy of psycho- and pharmacotherapy in panic disorder with and without agoraphobia. J Affect Disord 2005 Sep;88(1):27-45. [doi: 10.1016/j.jad.2005.05.003] [Medline: 16005982]

10. Sousa MB, Isolan LR, Oliveira RR, Manfro GG, Cordioli AV. A randomized clinical trial of cognitive-behavioral group therapy and sertraline in the treatment of obsessive-compulsive disorder. J Clin Psychiatry 2006 Jul;67(7):1133-1139. [Medline: 16889458]

11. Hofmann SG, Smits JA. Cognitive-behavioral therapy for adult anxiety disorders: a meta-analysis of randomized placebo-controlled trials. J Clin Psychiatry 2008 Apr;69(4):621-632 [FREE Full text] [Medline: 18363421]

12. Rosa-Alcázar AI, Sánchez-Meca J, Gómez-Conesa A, Marín-Martínez F. Psychological treatment of obsessive-compulsive disorder: a meta-analysis. Clin Psychol Rev 2008 Dec;28(8):1310-1325. [doi: 10.1016/j.cpr.2008.07.001] [Medline: $\underline{18701199]}$ 
13. Acarturk C, Cuijpers P, van Straten A, de Graaf R. Psychological treatment of social anxiety disorder: a meta-analysis. Psychol Med 2009 Feb;39(2):241-254. [doi: 10.1017/S0033291708003590] [Medline: 18507874]

14. Ougrin D. Efficacy of exposure versus cognitive therapy in anxiety disorders: systematic review and meta-analysis. BMC Psychiatry 2011 Dec 20;11:200 [FREE Full text] [doi: 10.1186/1471-244X-11-200] [Medline: 22185596]

15. Mayo-Wilson E, Dias S, Mavranezouli I, Kew K, Clark DM, Ades AE, et al. Psychological and pharmacological interventions for social anxiety disorder in adults: a systematic review and network meta-analysis. Lancet Psychiatry 2014 Oct;1(5):368-376 [FREE Full text] [doi: 10.1016/S2215-0366(14)70329-3] [Medline: 26361000]

16. Öst LG, Havnen A, Hansen B, Kvale G. Cognitive behavioral treatments of obsessive-compulsive disorder: a systematic review and meta-analysis of studies published 1993-2014. Clin Psychol Rev 2015 Aug;40:156-169. [doi: 10.1016/j.cpr.2015.06.003] [Medline: 26117062]

17. Ruskin PE, Silver-Aylaian M, Kling MA, Reed SA, Bradham DD, Hebel JR, et al. Treatment outcomes in depression: comparison of remote treatment through telepsychiatry to in-person treatment. Am J Psychiatry 2004 Aug;161(8):1471-1476. [doi: 10.1176/appi.ajp.161.8.1471] [Medline: 15285975]

18. Sorvaniemi M, Ojanen E, Santamäki O. Telepsychiatry in emergency consultations: a follow-up study of sixty patients. Telemed J E Health 2005 Aug;11(4):439-441. [doi: 10.1089/tmj.2005.11.439] [Medline: 16149889]

19. Nieminen K, Malmquist A, Wijma B, Ryding E, Andersson G, Wijma K. Nulliparous pregnant women's narratives of imminent childbirth before and after internet-based cognitive behavioural therapy for severe fear of childbirth: a qualitative study. BJOG 2015 Aug;122(9):1259-1265 [FREE Full text] [doi: 10.1111/1471-0528.13358] [Medline: 25817045]

20. Mathiasen K, Andersen TE, Riper H, Kleiboer AA, Roessler KK. Blended CBT versus face-to-face CBT: a randomised non-inferiority trial. BMC Psychiatry 2016 Dec 05;16(1):432 [FREE Full text] [doi: 10.1186/s12888-016-1140-y] [Medline: 27919234]

21. Calear AL, Christensen H. Review of internet-based prevention and treatment programs for anxiety and depression in children and adolescents. Med J Aust 2010 Jun 7;192(11 Suppl):S12-S14. [Medline: 20528700]

22. Farvolden P, Denisoff E, Selby P, Bagby RM, Rudy L. Usage and longitudinal effectiveness of a Web-based self-help cognitive behavioral therapy program for panic disorder. J Med Internet Res 2005;7(1):e7 [FREE Full text] [doi: 10.2196/jmir.7.1.e7] [Medline: 15829479$]$

23. Klein B, Meyer D, Austin DW, Kyrios M. Anxiety online: a virtual clinic: preliminary outcomes following completion of five fully automated treatment programs for anxiety disorders and symptoms. J Med Internet Res 2011;13(4):e89 [FREE Full text] [doi: 10.2196/jmir.1918] [Medline: 22057287]

24. Dear BF, Staples LG, Terides MD, Fogliati VJ, Sheehan J, Johnston L, et al. Transdiagnostic versus disorder-specific and clinician-guided versus self-guided internet-delivered treatment for social anxiety disorder and comorbid disorders: a randomized controlled trial. J Anxiety Disord 2016 Aug;42:30-44 [FREE Full text] [doi: 10.1016/j.janxdis.2016.05.004] [Medline: 27261562]

25. Proudfoot J, Clarke J, Birch MR, Whitton AE, Parker G, Manicavasagar V, et al. Impact of a mobile phone and web program on symptom and functional outcomes for people with mild-to-moderate depression, anxiety and stress: a randomised controlled trial. BMC Psychiatry 2013;13:312 [FREE Full text] [doi: 10.1186/1471-244X-13-312] [Medline: 24237617]

26. Andersson E, Enander J, Andrén P, Hedman E, Ljótsson B, Hursti T, et al. Internet-based cognitive behaviour therapy for obsessive-compulsive disorder: a randomized controlled trial. Psychol Med 2012 Oct;42(10):2193-2203 [FREE Full text] [doi: 10.1017/S0033291712000244] [Medline: 22348650]

27. Wootton BM, Dear BF, Johnston L, Terides MD, Titov N. Remote treatment of obsessive-compulsive disorder: a randomized controlled trial. J Obsess-Compuls Relat Disord 2013 Jan 20;2:375-384 [FREE Full text] [doi: 10.1016/j.jocrd.2013.07.002]

28. Bergström J, Andersson G, Ljótsson B, Rück C, Andréewitch S, Karlsson A, et al. Internet-versus group-administered cognitive behaviour therapy for panic disorder in a psychiatric setting: a randomised trial. BMC Psychiatry 2010;10:54 [FREE Full text] [doi: 10.1186/1471-244X-10-54] [Medline: 20598127]

29. Carlbring P, Nilsson-Ihrfelt E, Waara J, Kollenstam C, Buhrman M, Kaldo V, et al. Treatment of panic disorder: live therapy vs. self-help via the Internet. Behav Res Ther 2005 Oct;43(10):1321-1333. [doi: 10.1016/j.brat.2004.10.002] [Medline: $\underline{16086983]}$

30. Kiropoulos LA, Klein B, Austin DW, Gilson K, Pier C, Mitchell J, et al. Is internet-based CBT for panic disorder and agoraphobia as effective as face-to-face CBT? J Anxiety Disord 2008 Dec;22(8):1273-1284. [doi: 10.1016/j.janxdis.2008.01.008] [Medline: $\underline{18289829}$ ]

31. Wims E, Titov N, Andrews G, Choi I. Clinician-assisted Internet-based treatment is effective for panic: a randomized controlled trial. Aust N Z J Psychiatry 2010 Jul;44(7):599-607. [doi: 10.3109/00048671003614171] [Medline: 20560847]

32. Andersson G, Carlbring P, Holmström A, Sparthan E, Furmark T, Nilsson-Ihrfelt E, et al. Internet-based self-help with therapist feedback and in vivo group exposure for social phobia: a randomized controlled trial. J Consult Clin Psychol 2006 Aug;74(4):677-686. [doi: 10.1037/0022-006X.74.4.677] [Medline: 16881775]

33. Andrews G, Davies M, Titov N. Effectiveness randomized controlled trial of face to face versus Internet cognitive behaviour therapy for social phobia. Aust N Z J Psychiatry 2011 Apr;45(4):337-340. [doi: 10.3109/00048674.2010.538840] [Medline: 21323490] 
34. Berger T, Caspar F, Richardson R, Kneubühler B, Sutter D, Andersson G. Internet-based treatment of social phobia: a randomized controlled trial comparing unguided with two types of guided self-help. Behav Res Ther 2011 Mar;49(3):158-169. [doi: 10.1016/j.brat.2010.12.007] [Medline: 21255767]

35. Hedman E, Andersson G, Ljótsson B, Andersson E, Rück C, Mörtberg E, et al. Internet-based cognitive behavior therapy vs. cognitive behavioral group therapy for social anxiety disorder: a randomized controlled non-inferiority trial. PLoS One 2011;6(3):e18001 [FREE Full text] [doi: 10.1371/journal.pone.0018001] [Medline: 21483704]

36. Carlbring P, Andersson G, Cuijpers P, Riper H, Hedman-Lagerlöf E. Internet-based vs. face-to-face cognitive behavior therapy for psychiatric and somatic disorders: an updated systematic review and meta-analysis. Cogn Behav Ther 2018 Jan;47(1):1-18. [doi: 10.1080/16506073.2017.1401115] [Medline: 29215315]

37. American Psychiatric Association. Diagnostic and Statistical Manual of Mental Disorders, Third Edition. Arlington, VA, United States: American Psychiatric Publishing; 1980.

38. American Psychiatric Association. Diagnostic and Statistical Manual of Mental Disorders, Third Edition, Revised. Arlington, VA, United States: American Psychiatric Publishing; 1987.

39. American Psychiatric Association. Diagnostic and Statistical Manual of Mental Disorders, Fourth Edition. Arlington, VA, United States: American Psychiatric Publishing; 1994.

40. American Psychiatric Association. Diagnostic and Statistical Manual of Mental Disorders, Fourth Edition, Text Revision. Arlington, VA, United States: American Psychiatric Publishing; 2000.

41. World Health Organization. International Statistical Classification of Diseases and Related Health Problems, Ninth Revision. Geneva, Switzerland: World Health Organization; 1979.

42. World Health Organization. International Statistical Classification of Diseases and Related Health Problems, Tenth Revision. Geneva, Switzerland: World Health Organization; 1999.

43. Olthuis JV, Watt MC, Bailey K, Hayden JA, Stewart SH. Therapist-supported Internet cognitive behavioural therapy for anxiety disorders in adults. Cochrane Database Syst Rev 2015;3:CD011565. [doi: 10.1002/14651858.CD011565] [Medline: 25742186]

44. Lintvedt OK, Griffiths KM, Sørensen K, Østvik AR, Wang CEA, Eisemann M, et al. Evaluating the effectiveness and efficacy of unguided internet-based self-help intervention for the prevention of depression: a randomized controlled trial. Clin Psychol Psychother 2013;20(1):10-27. [doi: 10.1002/cpp.770] [Medline: 21887811]

45. Andersson G, Cuijpers P, Carlbring P, Riper H, Hedman E. Guided Internet-based vs. face-to-face cognitive behavior therapy for psychiatric and somatic disorders: a systematic review and meta-analysis. World Psychiatry 2014 Oct;13(3):288-295 [FREE Full text] [doi: 10.1002/wps.20151] [Medline: 25273302]

46. Kessler D, Lewis G, Kaur S, Wiles N, King M, Weich S, et al. Therapist-delivered internet psychotherapy for depression in primary care: a randomized controlled trial. Lancet 2009 Aug 22;374:628-634 [FREE Full text] [Medline: 19700005]

47. Storch EA, Caporino NE, Morgan JR, Lewin AB, Rojas A, Brauer L, et al. Preliminary investigation of web-camera delivered cognitive-behavioral therapy for youth with obsessive-compulsive disorder. Psychiatry Res 2011 Oct 30;189(3):407-412. [doi: 10.1016/j.psychres.2011.05.047] [Medline: 21684018]

48. Rees CS, Maclaine E. A systematic review of videoconference-delivered psychological treatment for anxiety disorders. Aust Psychol 2015 Jul 20;50(4):259-264 [FREE Full text]

49. Kishimoto T, Tarumi S, Nakamae T, Mimura M. [Exposure response prevention utilizing telemedicine-case series of three cases]. Jpn J Clin Psychiatry 2016 Aug 12;45(12):1603-1609 [FREE Full text]

50. Yuen EK, Herbert JD, Forman EM, Goetter EM, Juarascio AS, Rabin S, et al. Acceptance based behavior therapy for social anxiety disorder through videoconferencing. J Anxiety Disord 2013 May;27(4):389-397. [doi: 10.1016/j.janxdis.2013.03.002] [Medline: 23764124]

51. Vogel PA, Solem S, Hagen K, Moen EM, Launes G, Håland AT, et al. A pilot randomized controlled trial of videoconference-assisted treatment for obsessive-compulsive disorder. Behav Res Ther 2014 Oct 30;63:162-168. [doi: 10.1016/j.brat.2014.10.007] [Medline: 25461792]

52. Bouchard S, Paquin B, Payeur R, Allard M, Rivard V, Fournier T, et al. Delivering cognitive-behavior therapy for panic disorder with agoraphobia in videoconference. Telemed J E Health 2004;10(1):13-25. [doi: 10.1089/153056204773644535] [Medline: 15104911$]$

53. Sorvaniemi M, Ojanen E, Santamäki O. Telepsychiatry in emergency consultations: a follow-up study of sixty patients. Telemed J E Health 2005 Aug;11(4):439-441. [doi: 10.1089/tmj.2005.11.439] [Medline: 16149889]

54. McGrath JJ, Saha S, Al-Hamzawi A, Andrade L, Benjet C, Bromet EJ, et al. The bidirectional associations between psychotic experiences and DSM-IV mental disorders. Am J Psychiatry 2016 Oct 01;173(10):997-1006 [FREE Full text] [doi: 10.1176/appi.ajp.2016.15101293] [Medline: 26988628]

55. Simpson SG, Reid CL. Therapeutic alliance in videoconferencing psychotherapy: a review. Aust J Rural Health 2014 Dec;22(6):280-299. [doi: 10.1111/ajr.12149] [Medline: 25495622]

56. Mohr DC, Spring B, Freedland KE, Beckner V, Arean P, Hollon SD, et al. The selection and design of control conditions for randomized controlled trials of psychological interventions. Psychother Psychosom 2009;78(5):275-284. [doi:

10.1159/000228248] [Medline: 19602916] 
57. Sheehan DV, Lecrubier Y, Sheehan KH, Amorim P, Janavs J, Weiller E, et al. The Mini-International Neuropsychiatric Interview (M.I.N.I.): the development and validation of a structured diagnostic psychiatric interview for DSM-IV and ICD-10. J Clin Psychiatry 1998;59 Suppl 20:22-33;quiz 34. [Medline: 9881538]

58. Muramatsu K, Miyaoka H, Kamijima K, Muramatsu Y, Yoshida M, Otsubo T, et al. The patient health questionnaire, Japanese version: validity according to the mini-international neuropsychiatric interview-plus. Psychol Rep 2007 Dec;101(3 Pt 1):952-960. [doi: 10.2466/pr0.101.3.952-960] [Medline: 18232454$]$

59. Nakatani E, Nakagawa A, Nakao T, Yoshizato C, Nabeyama M, Kudo A, et al. A randomized controlled trial of Japanese patients with obsessive-compulsive disorder--effectiveness of behavior therapy and fluvoxamine. Psychother Psychosom 2005;74(5):269-276. [doi: 10.1159/000086317] [Medline: 16088264]

60. Seki Y, Nagata S, Shibuya T, Yoshinaga N, Yokoo M, Ibuki H, et al. A feasibility study of the clinical effectiveness and cost-effectiveness of individual cognitive behavioral therapy for panic disorder in a Japanese clinical setting: an uncontrolled pilot study. BMC Res Notes 2016 Oct 07;9(1):458 [FREE Full text] [doi: 10.1186/s13104-016-2262-5] [Medline: 27717407]

61. Yoshinaga N, Matsuki S, Niitsu T, Sato Y, Tanaka M, Ibuki H, et al. Cognitive behavioral therapy for patients with social anxiety disorder who remain symptomatic following antidepressant treatment: a randomized, assessor-blinded, controlled trial. Psychother Psychosom 2016;85(4):208-217 [FREE Full text] [doi: 10.1159/000444221] [Medline: 27230862]

62. Kobori O, Nakazato M, Yoshinaga N, Shiraishi T, Takaoka K, Nakagawa A, et al. Transporting cognitive behavioral therapy (CBT) and the Improving Access to Psychological Therapies (IAPT) project to Japan: preliminary observations and service evaluation in Chiba. J Ment Health Train Educ Pract 2014;9:155-166 [FREE Full text]

63. Blackburn IM, James IA, Milne DL, Baker C, Standart S, Garland A, et al. The Revised Cognitive Therapy Scale (CTS-R): psychometric properties. Behav Cogn Psychother 2001;29:431-446 [FREE Full text]

64. Shimizu E, Kobori O. Technique and therapeutic effect of Cognitive Therapy Scale-Revised. Jpn J Clin Psychiatry 2012;41(8):969-979.

65. Young JE, Beck AT. Cognitive Therapy Scale: rating manual. Philadelphia, PA: University of Pennsylvania; 1980 Aug 22. URL: https://cdn.ymaws.com/www.academyofct.org/resource/collection/24743CF7-351E-4335-9E93-83F26EF675A3/ CTRS_Manual.pdf [accessed 2018-12-02] [WebCite Cache ID 74Mm51FFC]

66. Young JE, Beck AT. Cognitive Therapy Scale. Philadelphia, PA: University of Pennsylvania; 1988.

67. Shabiralyani G, Hasan KS, Hamad N, Iqbal N. Impact of visual aids in enhancing the learning process case research: district Dera Ghazi Khan. J Educ Pract 2015;6:226-233 [FREE Full text]

68. Ministry of Health, Labour and Welfare, Japan. 2016. Guideline on Safety Management of Medical Information System Version 4 URL: https://www.mhlw.go.jp/stf/shingi2/0000119588.html [accessed 2018-12-02] [WebCite Cache ID 74MmGbpmW]

69. Goodman WK, Price LH, Rasmussen SA, Mazure C, Fleischmann RL, Hill CL, et al. The Yale-Brown Obsessive Compulsive Scale. I. Development, use, and reliability. Arch Gen Psychiatry 1989 Nov;46(11):1006-1011. [Medline: 2684084]

70. Hamagaki S, Takagi S, Urushihara Y, Ishisaka Y, Matsumoto M. [Development and use of the Japanese version of the self-report Yale-Brown Obsessive Compulsive Scale]. Seishin Shinkeigaku Zasshi 1999;101(2):152-168. [Medline: $\underline{10375975]}$

71. Houck PR, Spiegel DA, Shear MK, Rucci P. Reliability of the self-report version of the Panic Disorder Severity Scale. Depress Anxiety 2002;15(4):183-185. [doi: 10.1002/da.10049] [Medline: 12112724]

72. Katagami M. The self-report version of the Panic Disorder Severity Scale: reliability and validity of the Japanese version. Jpn J Psychosom Med 2007;47:331-338 [FREE Full text]

73. Liebowitz MR. Social phobia. Mod Probl Pharmacopsychiatry 1987;22:141-173. [Medline: 2885745]

74. Asakura S, Inoue S, Sasaki F, Sasaki Y, Kitagawa N, Inoue T, et al. Consideration of validity and reliability for Liebowitz Social Anxiety Scale (LSAS) Japanese version. Clin Psychiatry 2002;177:1084.

75. Farris SG, McLean CP, Van Meter PE, Simpson HB, Foa EB. Treatment response, symptom remission, and wellness in obsessive-compulsive disorder. J Clin Psychiatry 2013 Jul;74(7):685-690 [FREE Full text] [doi: 10.4088/JCP.12m07789] [Medline: 23945445]

76. Furukawa TA, Katherine SM, Barlow DH, Gorman JM, Woods SW, Money R, et al. Evidence-based guidelines for interpretation of the Panic Disorder Severity Scale. Depress Anxiety 2009;26(10):922-929 [FREE Full text] [doi: 10.1002/da.20532] [Medline: 19006198]

77. EuroQol Group. EuroQol--a new facility for the measurement of health-related quality of life. Health Policy 1990 Dec;16(3):199-208. [Medline: 10109801]

78. Tsuchiya A, Ikeda S, Ikegami N, Nishimura S, Sakai I, Fukuda T, et al. Estimating an EQ-5D population value set: the case of Japan. Health Econ 2002 Jun;11(4):341-353. [doi: 10.1002/hec.673] [Medline: 12007165]

79. Tracey TJ, Kokotovic AM. Factor structure of the Working Alliance Inventory. Psychol Assess 1989;1(3):207-210. [doi: 10.1037/1040-3590.1.3.207]

80. Spitzer RL, Kroenke K, Williams JB. Validation and utility of a self-report version of PRIME-MD: the PHQ primary care study. Primary Care Evaluation of Mental Disorders. Patient Health Questionnaire. J Am Med Assoc 1999 Nov 10;282(18):1737-1744. [Medline: 10568646] 
81. Muramatsu K. Patient Health Questionnaire (PHQ-9, PHQ-15) Japanese version and Generalized Anxiety Disorder-7 Japanese version?up to date. Stud Clin Psychol 2014;7:35-39 [FREE Full text]

82. Spitzer RL, Kroenke K, Williams JB, Löwe B. A brief measure for assessing Generalized Anxiety Disorder: the GAD-7. Arch Intern Med 2006 May 22;166(10):1092-1097. [doi: 10.1001/archinte.166.10.1092] [Medline: 16717171]

83. Muramatsu K, Miyaoka H, Uesima K, Muramatsu Y, Fuse K, Yoshimine F, et al. Examination of validity and usefulness of GAD-7 Japanese version. Jpn Soc Psychosom Med 2010;50(6):592.

84. Eysenbach G, CONSORT-EHEALTH Group. CONSORT-EHEALTH: improving and standardizing evaluation reports of Web-based and mobile health interventions. J Med Internet Res 2011;13(4):e126 [FREE Full text] [doi: 10.2196/jmir.1923] [Medline: 22209829]

85. Cohen J. Statistical Power Analysis for the Behavioral Sciences. 2nd Edition. Hillsdale, NJ: Lawrence Erlbaum Associates; 1988.

86. Nakao S, Nakagawa A, Oguchi Y, Mitsuda D, Kato N, Nakagawa Y, et al. Web-based cognitive behavioral therapy blended with face-to-face sessions for major depression: randomized controlled trial. J Med Internet Res 2018 Sep 21;20(9):e10743 [FREE Full text] [doi: 10.2196/10743] [Medline: $\underline{\text { 30249583] }}$

87. Loerinc AG, Meuret AE, Twohig MP, Rosenfield D, Bluett EJ, Craske MG. Response rates for CBT for anxiety disorders: need for standardized criteria. Clin Psychol Rev 2015 Dec;42:72-82. [doi: 10.1016/j.cpr.2015.08.004] [Medline: 26319194]

88. Payakachat N, Ali MM, Tilford JM. Can The EQ-5D detect meaningful change? A systematic review. Pharmacoeconomics 2015 Nov;33(11):1137-1154 [FREE Full text] [doi: 10.1007/s40273-015-0295-6] [Medline: 26040242]

89. Williams MD, Sawchuk CN, Shippee ND, Somers KJ, Berg SL, Mitchell JD, et al. A quality improvement project aimed at adapting primary care to ensure the delivery of evidence-based psychotherapy for adult anxiety. Br Med J Open Qual 2018;7(1):e000066 [FREE Full text] [doi: 10.1136/bmjoq-2017-000066] [Medline: 29333493]

90. Haug T, Nordgreen T, Öst LG, Tangen T, Kvale G, Hovland OJ, et al. Working alliance and competence as predictors of outcome in cognitive behavioral therapy for social anxiety and panic disorder in adults. Behav Res Ther 2016 Feb;77:40-51. [doi: 10.1016/j.brat.2015.12.004] [Medline: 26708332]

91. Swift JK, Greenber RP. A treatment by disorder meta-analysis of dropout from psychotherapy. J Psychother Integr 2014;24:193-207 [FREE Full text]

92. Öst LG, Havnen A, Hansen B, Kvale G. Cognitive behavioral treatments of obsessive-compulsive disorder. A systematic review and meta-analysis of studies published 1993-2014. Clin Psychol Rev 2015 Aug;40:156-169. [doi:

10.1016/j.cpr.2015.06.003] [Medline: 26117062]

93. Mitte K. A meta-analysis of the efficacy of psycho- and pharmacotherapy in panic disorder with and without agoraphobia. J Affect Disord 2005 Sep;88(1):27-45. [doi: 10.1016/j.jad.2005.05.003] [Medline: 16005982]

\author{
Abbreviations \\ AMED: Agency for Medical Research and Development \\ CBT: cognitive behavioral therapy \\ DSM: Diagnostic and Statistical Manual of Mental Disorders \\ EQ-5D: EuroQol-5 Dimension \\ GAD-7: Generalized Anxiety Disorder-7 \\ ICBT: internet-delivered CBT \\ LSAS: Liebowitz Social Anxiety Scale \\ OCD: obsessive-compulsive disorder \\ PD: panic disorder \\ PDSS: Panic Disorder Severity Scale \\ PHQ-9: Patient Health Questionnaire-9 \\ PTSD: posttraumatic stress disorder \\ SAD: social anxiety disorder \\ WAI-SF: Working Alliance Inventory-Short Form \\ Y-BOCS: Yale-Brown Obsessive-Compulsive Scale
}


Edited by C Eichenberg; submitted 05.09.18; peer-reviewed by K Mathiasen, E Aboujaoude, M Ak; comments to author 26.09.18; revised version received 29.10.18; accepted 11.11.18; published 17.12.18

Please cite as:

Matsumoto K, Sutoh C, Asano K, Seki Y, Urao Y, Yokoo M, Takanashi R, Yoshida T, Tanaka M, Noguchi R, Nagata S, Oshiro K, Numata N, Hirose M, Yoshimura K, Nagai K, Sato Y, Kishimoto T, Nakagawa A, Shimizu E

Internet-Based Cognitive Behavioral Therapy With Real-Time Therapist Support via Videoconference for Patients With Obsessive-Compulsive Disorder, Panic Disorder, and Social Anxiety Disorder: Pilot Single-Arm Trial

J Med Internet Res 2018;20(12):e12091

URL: http://www.jmir.org/2018/12/e12091/

doi: $10.2196 / 12091$

PMID: 30559094

CKazuki Matsumoto, Chihiro Sutoh, Kenichi Asano, Yoichi Seki, Yuko Urao, Mizue Yokoo, Rieko Takanashi, Tokiko Yoshida, Mari Tanaka, Remi Noguchi, Shinobu Nagata, Keiko Oshiro, Noriko Numata, Motohisa Hirose, Kensuke Yoshimura, Kazue Nagai, Yasunori Sato, Taishiro Kishimoto, Akiko Nakagawa, Eiji Shimizu. Originally published in the Journal of Medical Internet Research (http://www.jmir.org), 17.12.2018. This is an open-access article distributed under the terms of the Creative Commons Attribution License (https://creativecommons.org/licenses/by/4.0/), which permits unrestricted use, distribution, and reproduction in any medium, provided the original work, first published in the Journal of Medical Internet Research, is properly cited. The complete bibliographic information, a link to the original publication on http://www.jmir.org/, as well as this copyright and license information must be included. 